MATEC Web of Conferences 25, 04001 (2015)

DOI: $10.1051 /$ matec conf/20152504001

(C) Owned by the authors, published by EDP Sciences, 2015

\title{
Research of Optimal Experiment on Bridge Pier Types for Reducing Backwater
}

\author{
Zhenjun He, Jinming Zhang, Yong He \& Shousheng Mu \\ The Pearl River Hydraulic Research Institute, Guangdong, Guangzhou, China
}

\begin{abstract}
There are many kinds of commonly-used bridge pier types. This paper researches the selection principle and optimal type of the bridge pier types from the perspective of reducing backwater. This paper also tests and analyzes the high resistance water for different types of bridge pier under different flow velocities and conditions of water resistance ratio through establishment of a physical model of wide water channel. The result shows that, the bridge pier has an optimal profile curve, and the characteristic parameter $\left(b^{\prime} / \mathrm{L}\right)$ is from 0.071 to 0.083; three kinds of commonly-used pier types - square pier, streamline pier and bicircular pier have different strength angles. If the angle between the axis of bridge pier and the water flow direction is less than $36^{\circ}$, it should give priority to the streamline pier; if the angle is greater than $36^{\circ}$, then it should give priority to the bicircular pier.
\end{abstract}

Keywords: backwater at bridge piers; bridge pier types; type optimization

\section{RESEARCH BACKGROUND}

The investigation, analysis and experimental research on bridge backwater started from the end of last century in foreign countries with a starting point of calculation formula of backwater at bridge piers proposed by D'Aubuisson in 1840, and its history is more than 170 years. Later, Weisbach (1848), Ruhlmann (1880), et al. respectively proposed the weir flow formula of backwater at bridge piers; Naglar (1917), Lane (1920) adopted experimental data to revise D'Aubuisson formula and Weisbach formula. Then, Rehbock and Yarnell respectively carried out a large number of systematic laboratory experiments, thus pushing ahead previous research based on distinguishing flow state. Since the $1960 \mathrm{~s}$, the electronic computer has been used for calculation of bridge and river water in foreign countries. From the late 1960s to the early 1970s, the Geological Engineering Center of United States Army Corps of Engineers and other departments prepared calculation procedures for bridge river hydraulics and culverts hydraulics. In 1974, the United States J.T.Franques and D.W.Yannitell prepared the first finite element model in two-dimensional flow analysis of backwater before the bridge. Until recently, with the improvement of calculation methods and model discrete methods, there were many calculation procedures with more accuracy, such as PHOENICS, CFX, STAR-CD, MIKE, FLUENT and other commercial CFD software.

Chinese railway department began to research this issue since the late 1970s. After the great flood of the Yangtze River in 1998, the Water Conservancy Department researched this issue with gradually increasing number. Combined with hydraulic model test data, Kai Wang, Xudong Fu, Guangxian Wang (2006) car- ried out the contrast test for Yarnell formula, D'Aubuisson formula, Henderson formula and non-ridge broad-crested weir formula and analyzed applicable conditions and deviations of different formulas. Combined with specific engineering and numerical simulation methods, Beilei Qin (2010) analyzed the errors and reasons of these four formulas. Currently, there are many results of bridge backwater by the use of numerical simulation methods. Cuiling Sun, Xiaohui Xu, et al. (2006) carried out mathematical model analysis of joint water resistance effect for many bridges in Foshan City; Linchun Xu, Dong Huang, et al. (2008) adopted the numerical simulation methods to analyze the flood influence on Beijiang Baimiao Extra Large Bridge Engineering; Fei Wu, Meng Gan (2009) adopted the numerical simulation methods to analyze the influence on the river flow field by bigger angle between the axis of the pier group and the river flow direction; Qin Zhou, Chongqing Yin, et al. (2011) adopted the numerical simulation methods to analyze the water resistance properties for the skew bridge pier; Wei Ding, Hongwu Tang, et al. (2011) adopted the numerical simulation methods to analyze the resistance influence factors of river bridges.

With the rapid development of chinese society and economy, there is a higher requirement on flood control safety. How to optimize engineering design plan of river bridges, adapt to the dynamic characteristics of river water, and reduce backwater to control the impact of engineering on the flood control are not only important technical issues that trouble the engineering construction and design units, but also key technical issues for the water administrative department to carry out river management and water administrative licenses. For the calculation of backwater at the bridge 


\section{MATEC Web of Conferences}

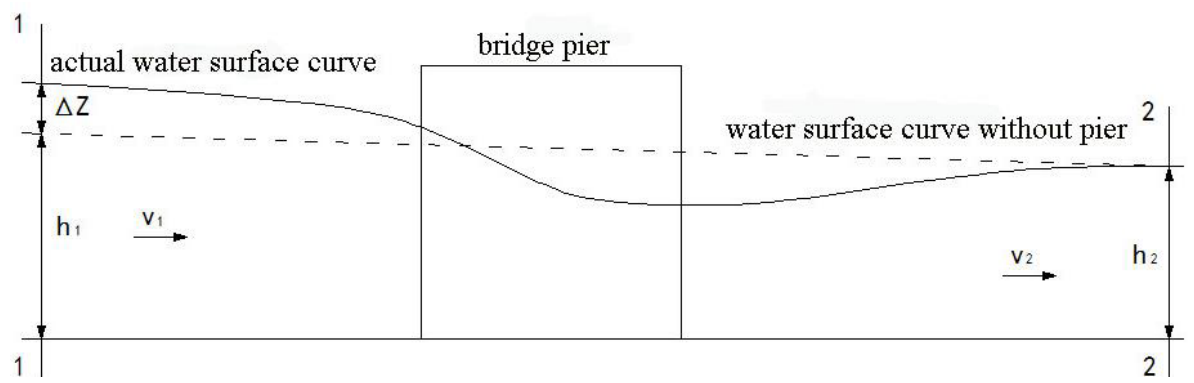

Figure 1. Schematic diagram of backwater at the bridge pier

piers, domestic and foreign scholars have conducted extensive research. However, so far, few people have researched how to optimize the types of bridge pier from the perspective of reducing Backwater level, which is the key point of the current research.

\section{ANALYSIS OF INFLUENCE FACTORS OF BACKWATER AT BRIDGE PIERS}

Due to hindering effect of the bridge pier, water flow requires to overcome resistance when passing through the bridge pier, resulting in the formation of certain backwater level up before the bridge pier. It is shown in Figure 1. In case of no bridge pier, the frictional head loss caused by river bed roughness is $\Delta h_{p}=h_{1}-h_{2}$; in case of bridge pier, the total head loss of backwater $\Delta \mathrm{z}$ is as follows:

$$
\begin{aligned}
& \Delta \mathrm{h}=\Delta \mathrm{h}_{\mathrm{p}}+\Delta \mathrm{h}_{\mathrm{s}}=\Delta \mathrm{Z}+\mathrm{h}_{1}-\mathrm{h}_{2}+\alpha_{1} \frac{\mathrm{v}_{1}^{2}}{2 \mathrm{~g}}-\alpha_{2} \frac{\mathrm{v}_{2}^{2}}{2 \mathrm{~g}} \\
& =\Delta \mathrm{Z}+\Delta \mathrm{h}_{\mathrm{p}}+\alpha_{1} \frac{\mathrm{v}_{1}^{2}}{2 \mathrm{~g}}-\alpha_{2} \frac{\mathrm{v}_{2}^{2}}{2 \mathrm{~g}} \\
& \text { Then: } \Delta h_{s}=\Delta Z+\alpha_{1} \frac{v_{1}^{2}}{2 g}-\alpha_{2} \frac{v_{2}^{2}}{2 g}
\end{aligned}
$$

Where, $\Delta h, \Delta h_{p}$ and $\Delta h_{s}$ respectively represent the total head loss, the frictional head loss and the local head loss; $\alpha_{1}$ and $\alpha_{2}$ respectively represent the kinetic energy correction factors of the section 1-1 and section 2-2. In general, Backwater level $\Delta z$ caused by wading buildings is smaller than the water depth $h_{1}$, $h_{2}$; the flow velocity of wading buildings is approximately equal, and the kinetic energy correction factor is also approximately equal, that is, $v_{1} \approx v_{2}, \alpha_{1} \approx \alpha_{2}$, then:

$$
\Delta h_{S} \approx \Delta Z
$$

According to the formula of local head loss:

$$
\Delta H_{s}=\zeta \bullet v_{2}^{2} / 2 g \approx \Delta Z
$$

Where $\zeta$ is the coefficient of local head loss. Such derivation shows that, the backwater level formed by water resistance of bridge is equal to the local head loss when water flows though the bridge. The local head loss caused by the bridge consists of four parts:

1. The head loss caused by shrinkage of upstream streamline: The more severe the streamline shrinks, the greater the head loss will be.

2 . The head loss caused by backflow due to formation of the shrinkage of upstream streamline: The greater the backflow intensity is, the greater the backflow range is, and the greater the head loss is;

3 . The head loss caused by diffusion of downstream streamline: The more severe the streamline diffuses, the greater the head loss;

4. The head loss caused by backflow due to diffusion of the shrinkage of downstream streamline: The greater the backflow intensity is, the greater the backflow range is, and the greater the head loss is.

The factors affecting four parts of the local head loss are the factors affecting backwater level. Some factors do not affect or have a little effect on the local head loss, so they are not major factors affecting backwater level, such as gradient of river bed and river bed roughness. Major factors affecting backwater level from the perspective of engineering application are as follows:

1. Flow velocity: a main parameter to measure flow characteristics. The greater the flow velocity is, the greater the flow inertia is, the more severe the streamline shrinks or diffuses and the greater the backflow intensity is.

2. Water resistance ratio: a main parameter to measure the relation between wading building and river channel. The greater the water resistance ratio is, the more severe the streamline shrinks or diffuses, and the greater the backflow intensity is.

3. Bridge structure: bridge structure affects shrinkage or diffusion of streamline and backflow range, mainly including the upstream face shape of the bridge, the side view and façade type and so on.

\section{ESTABLISHMENT OF A PHYSICAL MODEL OF WIDE WATER CHANNEL}

The backwater level caused by water resistance at the current bridge pier is only a few centimeters, which is very high demanding on the accuracy of the physical 
model test. On one hand, the water channel model requires sufficient breadth to reduce the impact of side wall on water flow; on the other hand, the test equipment requires sufficient accuracy to guarantee the effective operation of the test equipment.

\subsection{Design and manufacturing of wide water channel model}

The physical model of wide water channel is designed based on the gravity similarity criteria and geometric similarity criteria with the length of water channel which is $50 \mathrm{~m}$, the breadth which is $3 \mathrm{~m}$ and the height which is $0.7 \mathrm{~m}$. It mainly meets the similarity of water flow movement. The entire model is comprised of the circulating pool, flat water tower, measuring weir, forebay section, test section of wide water channel and tail-gate section as a closed system. During the test, water pump absorbs water from the circulating pool in the flat water tower, which successively passes through the measuring weir, forebay section and test section of wide water channel, and finally passes through tail gate and flows back to the circulating pool. The maximum output of supplying water of the model in the system is $0.53 \mathrm{~m}^{3} / \mathrm{s}$.

The baseboard of wide water channel is a flat slope, and the height accuracy is controlled within $0.2 \mathrm{~mm}$; the absolute error of the breadth of water channel is less than $2.0 \mathrm{~mm}$, and nonperpendicularity of its wall is less than $0.2^{\circ}$. When the water depth is measured at 5 $40 \mathrm{~cm}$ through the test, the composite roughness of the wide water channel is between 0.013 and 0.016 . The bridge model is manufactured by PVC tube and cement, which goes through sand papering, with the roughness of being from 0.010 to 0.012 . The local resistance of the bridge is related to turbulent flow state, so the water flow of the model is required to be turbulent state. According to the water depth of the model in the test and the flow velocity and kinematic viscosity coefficient of water $\left(v=0.0101 \mathrm{~cm}^{2} / \mathrm{s}\right)$, the minimum Reynolds number of the model can be calculated $\operatorname{Re}=U h / v>1000 \sim 2000$. which is turbulent restrictions selected by the model scale.

Under different test conditions, the maximum Backwater level caused by water resistance in the project is different in different locations of the engineering upstream. To ensure the test of the maximum Backwater level, 15 water level measurement points are set up in the test in longitudinal center line of the wide water channel with the measuring point spacing which is $2 \mathrm{~m}$ while tracking the changes of water level.

\subsection{Test equipment and accuracy guarantee}

To ensure the accuracy of the model test, the model geometry scale is controlled below 25 . The test is carried out under indoor windless conditions. The measuring points are connected to the side-wall cylinder through communicating pipe, so as to avoid the impact of small waves on the water surface on the water level test; the water level measurement adopts the GS-3B grating track water level gauge with the accuracy of $0.1 \mathrm{~mm}$. The water level gauge automatically measures water level by the computer system to avoid the error of manual readings. The model measurement and control system adopts distributed industrial control system, which can automatically store various parameters of the model test and display the real-time water level curves, the historical test data and data acquisition and so on.

\section{RESEARCH OF OPTIMAL EXPERIMENT ON BRIDGE PIER TYPES}

\subsection{Optimization of bridge pier types}

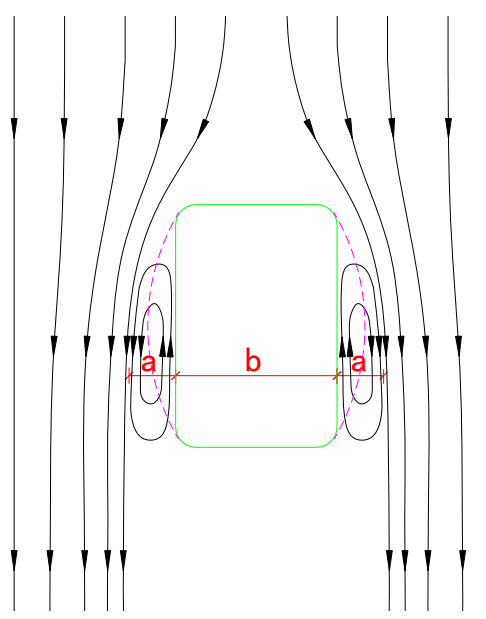

Figure 2. Schematic diagram of streaming around the bridge pier

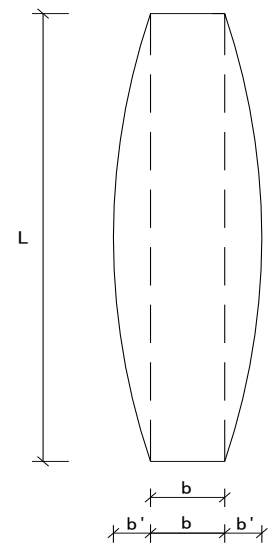

Figure 3. Program of optimal experiment on bridge pier types

When the incoming flow passes through the bridge pier, it forms flow around both sides of the pier head, and forms a recirculation zone in the local range on both sides of the bridge pier, which is shown in Figure 3 . The actual breadth of water resistance caused by the 


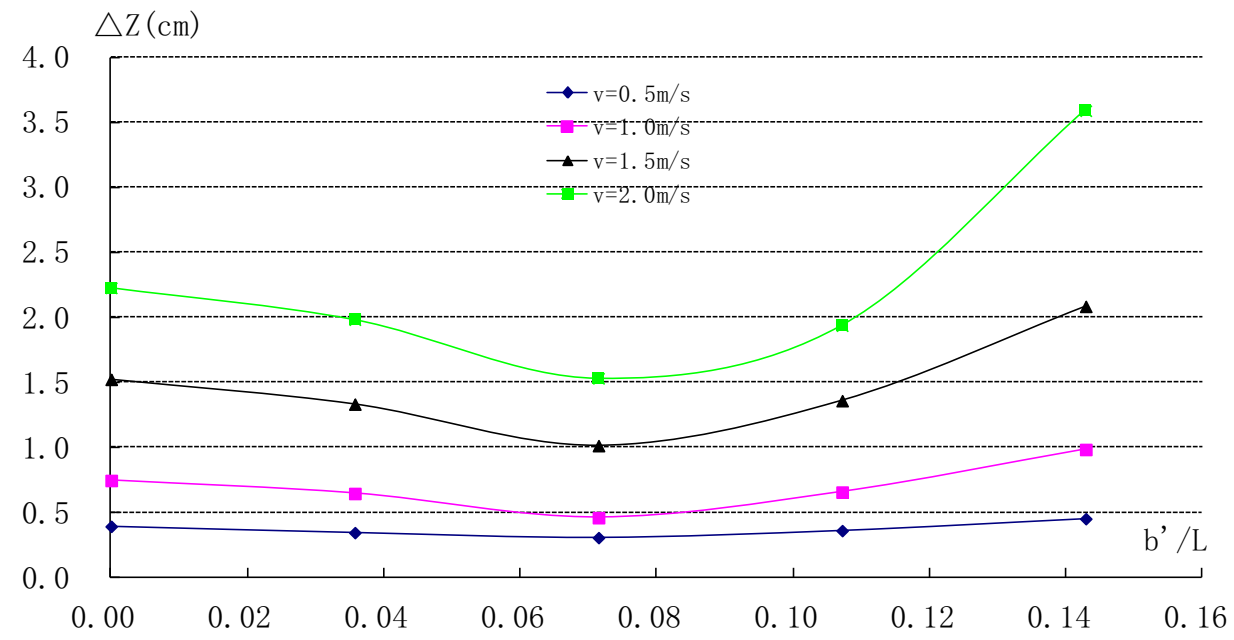

Figure 4. Backwater level based on different profile curves of the bridge pier $(b / L=1: 7)$

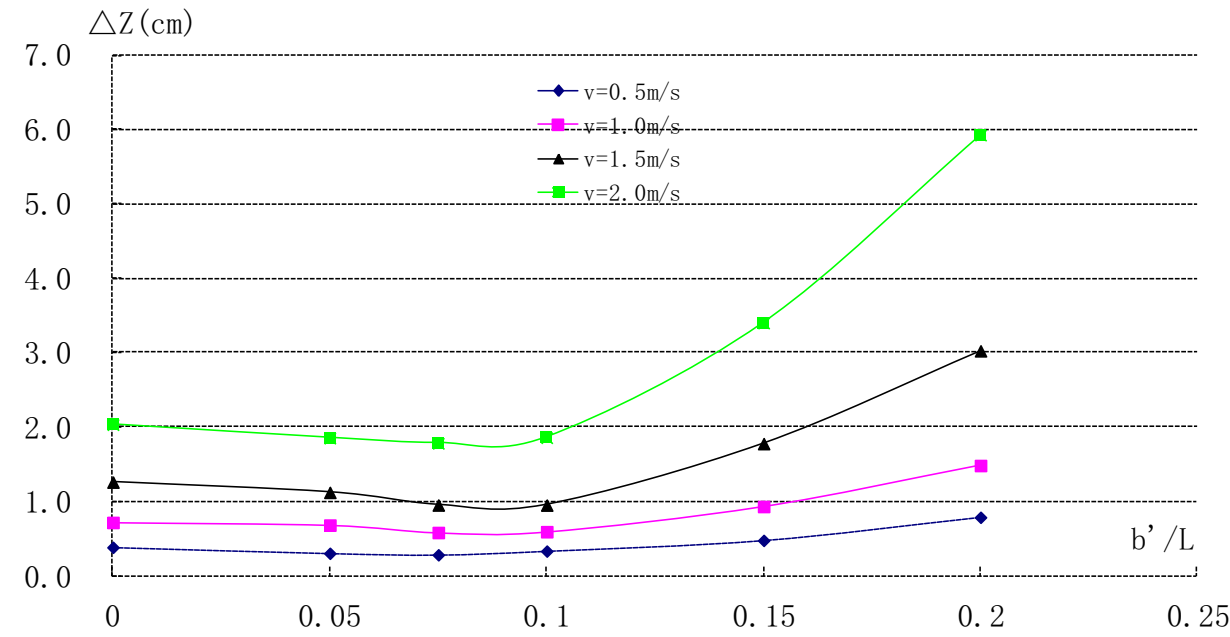

Figure 5. Backwater level based on different profile curves of the bridge pier ( $b$ / $L=1: 5)$

bridge pier is a sum of the breadth of bridge pier and the breadth of the recirculation zone, that is, $(b+2 a)$. The larger the breadth of the recirculation zone is, the larger the breadth of the actual water resistance is. And the water backflow within the range of the recirculation zone consumes additional energy, the larger the upstream backwater level is. When the incoming flow conditions and breadth of upstream face of the bridge pier are fixed, the bridge pier type determines the backflow scope and backflow intensity. Optimization of the bridge pier type can reduce the backflow scope and backflow intensity, thus reducing the backwater level.

Based on the optimization ideas, when the frontier breadth of upstream face of the bridge pier is un- changed, the profile curve of the bridge pier is amended as an arc, and then the profile curve of the bridge pier has an optimal value. That is, the amendment of the profile curve of the bridge pier does not affect the streamline shrinkage on both sides of the bridge pier, but it can reduce the backflow scope and the backflow intensity on both sides of the bridge pier, and improve flow expansion and adjustment behind the bridge pier. Test programs and test results are shown in Figure 3 and Table 1. In the test, the frontier breadth of upstream face of the bridge pier (b) is $2 \mathrm{~m}$; the spacing of the bridge pier (B) is $33.33 \mathrm{~m}$; the model scale is 22.22 . L is the length of the bridge pier, and b' is the breadth of arc on the side of the bridge pier. 


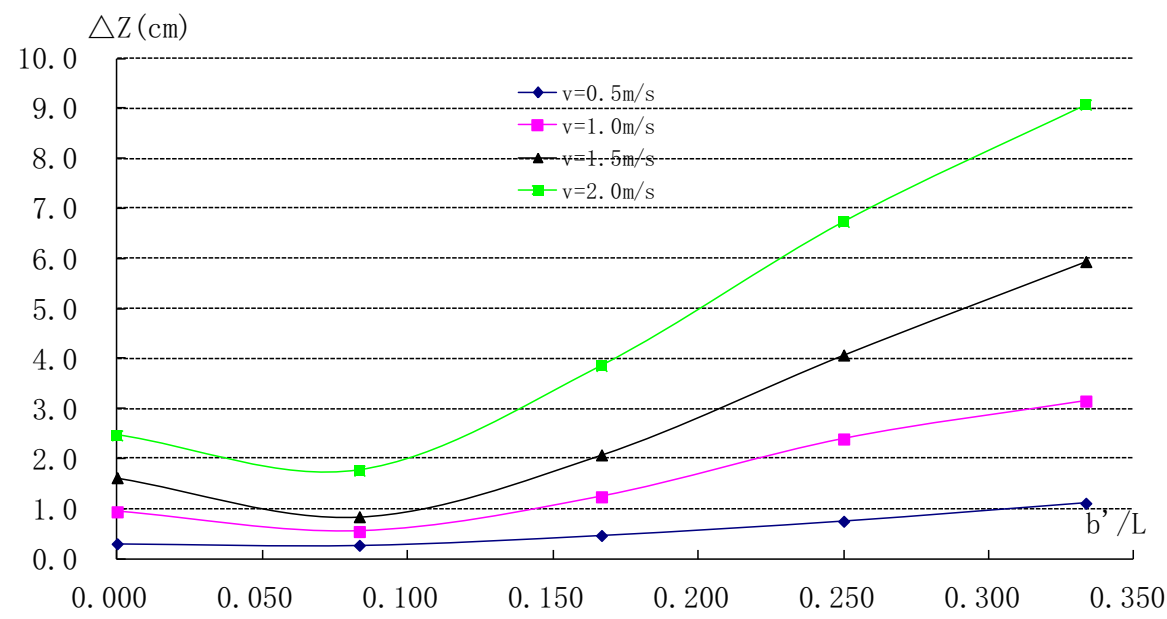

Figure 6. Backwater level based on different profile curves of the bridge pier $(\mathrm{b} / \mathrm{L}=1: 3)$

Table 1. Optimal program of bridge pier types and experimental results

\begin{tabular}{|c|c|c|c|c|c|c|c|}
\hline \multirow[b]{2}{*}{$\mathrm{L}(\mathrm{m})$} & \multirow[b]{2}{*}{$\mathrm{b} / \mathrm{L}$} & \multirow[b]{2}{*}{$b^{\prime}(m)$} & \multirow[b]{2}{*}{$b^{\prime} / L$} & \multicolumn{4}{|c|}{ Backwater level $(\mathrm{cm})$} \\
\hline & & & & $\begin{array}{l}0.5 \\
\mathrm{~m} / \mathrm{s}\end{array}$ & $\begin{array}{l}1.0 \\
\mathrm{~m} / \mathrm{s}\end{array}$ & $\begin{array}{l}1.5 \\
\mathrm{~m} / \mathrm{s}\end{array}$ & $\begin{array}{l}2.0 \\
\mathrm{~m} / \mathrm{s}\end{array}$ \\
\hline \multirow{5}{*}{14} & \multirow{5}{*}{$1: 7$} & 0 & 0 & 0.39 & 0.74 & 1.52 & 2.22 \\
\hline & & 0.5 & 0.036 & & 0.64 & 1.33 & 1.98 \\
\hline & & 1 & 0.071 & 0.30 & 0.46 & 1.01 & 1.53 \\
\hline & & 1.5 & 0.107 & 0.36 & 0.65 & 1.36 & 1.93 \\
\hline & & 2 & 0.143 & 0.45 & 0.98 & 2.08 & 3.59 \\
\hline \multirow{6}{*}{10} & \multirow{6}{*}{$1: 5$} & 0 & 0 & 0.38 & 0.72 & 1.26 & 2.03 \\
\hline & & 0.5 & 0.05 & 0.30 & 0.68 & 1.12 & 1.85 \\
\hline & & 0.75 & 0.075 & 0.28 & 0.58 & 0.95 & 1.78 \\
\hline & & 1 & 0.1 & 0.33 & 0.59 & 0.95 & 1.85 \\
\hline & & 1.5 & 0.15 & 0.47 & 0.93 & 1.78 & 3.40 \\
\hline & & 2 & 0.2 & 0.78 & 1.48 & 3.02 & 5.93 \\
\hline \multirow{5}{*}{6} & \multirow{5}{*}{$1: 3$} & 0 & 0 & 0.30 & 0.93 & 1.62 & 2.46 \\
\hline & & 0.25 & 0.083 & 0.27 & 0.54 & 0.84 & 1.76 \\
\hline & & 0.5 & 0.167 & 0.46 & 1.23 & 2.07 & 3.85 \\
\hline & & 0.75 & 0.250 & 0.75 & 2.39 & 4.07 & 6.73 \\
\hline & & 1 & 0.333 & 1.11 & 3.15 & 5.94 & 9.07 \\
\hline
\end{tabular}

The ratio between the convex breadth of the curve (b') and the length of bridge pier (L) is a dimensionless number to measure the degree of curvature of the curve, and then a relation curve of backwater level and b'/L can be developed, which is shown in Figure 4 to Figure 6 . As can be seen from Table 1 and Figures 4 to 6 , the backwater level in various programs has a minimum value. The characteristic parameter in the profile curve of the bridge pier under the minimum backwater level $\left(b^{\prime} / L\right)$ is $0.071-0.083$.

\subsection{Selection of bridge pier types}

The types of wading bridge pier are mainly bicircular pier, square pier with lead angles and streamline pier and so on. The test carries out experimental research on these three kinds of representative pier types. Figure 7 to Figure 9 shows the bridge pier type and size adopted by the project in the Pearl River estuary.

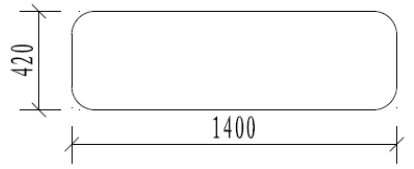

Figure 7. Water resistance cross section and dimension of square pier (unit: $\mathrm{cm}$, the same below)

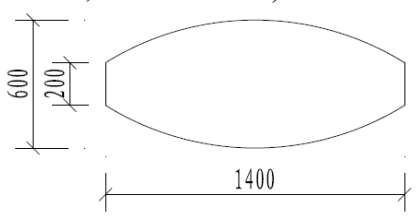

Figure 8. Water resistance cross section and dimension of streamline pier

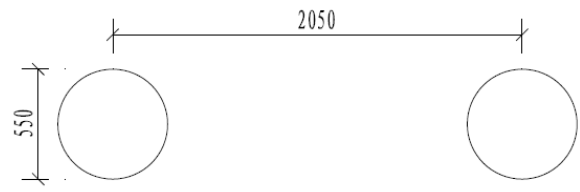

Figure 9. Water resistance cross section and dimension of bicircular pier 


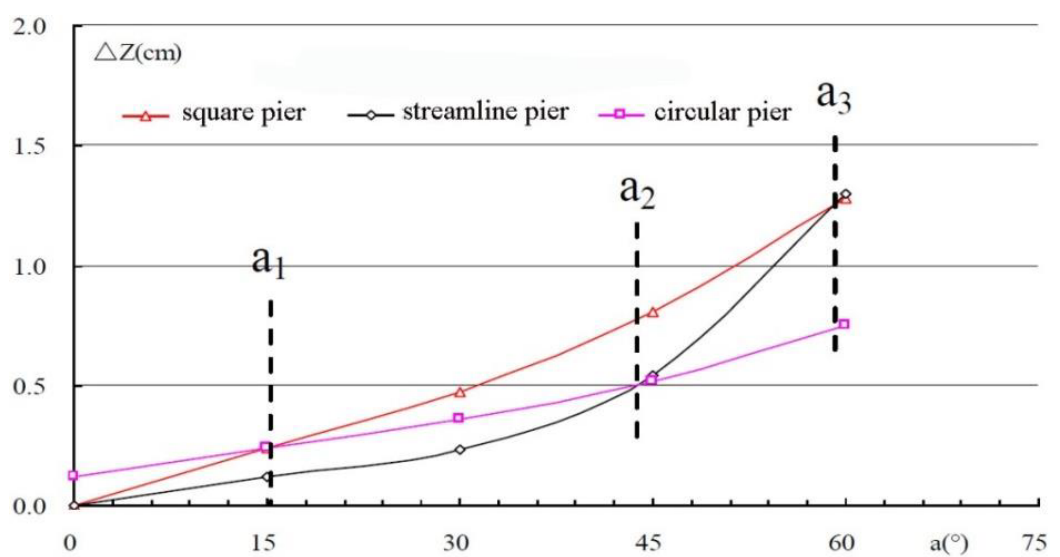

Figure 10. Relationship between the upstream backwater level and the pier type $(\mathrm{v}=0.5 \mathrm{~m} / \mathrm{s})$

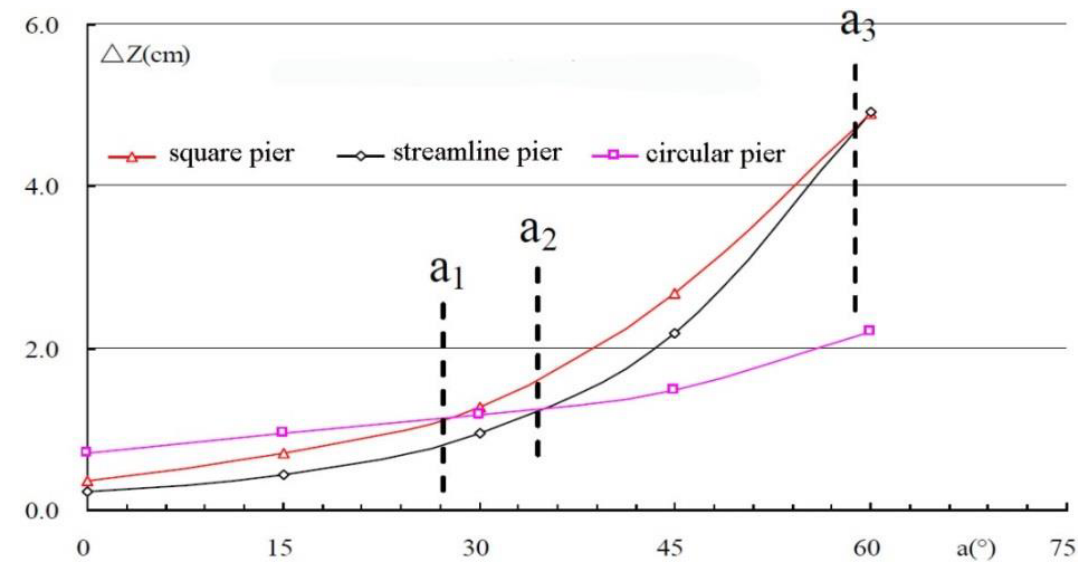

Figure 11. Relationship between the upstream backwater level and the pier type $(\mathrm{v}=1.0 \mathrm{~m} / \mathrm{s})$

Table 2 shows the experimental data related to the impact of the bridge pier type, the angle between the axis of the bridge pier and the water flow direction on backwater. According to the data in Table 2, a relation curve of backwater level and bridge pier type can be developed, which is shown in Figures 10 to 13 . As can be seen from the figures, under different flow velocities, the backwater level caused by three pier types represents the same rule with the relationship between the bridge pier axis and the flow angle and it is shown as follows.

1. When the angle between the axis of the bridge pier and water flow direction is less than $\alpha_{1}$, the upstream backwater level caused by bicircular pier is the largest, and larger the square pier is, the smallest the streamline pier is.

2. When the angle between the axis of the bridge pier and the water flow direction is between $\alpha_{1}$ and $\alpha_{2}$, the upstream backwater level caused by square pier is the largest, and the larger the bicircular pier is, the smallest streamline pier is.
3. When the angle between the axis of the bridge pier and the water flow direction is between $\alpha_{2}$ and $\alpha_{3}$ the upstream backwater level caused by square pier is the largest. As the streamline pier is becoming larger, the bicircular pier is gradually becoming the smallest.

4. When the angle between the axis of the bridge pier and water flow direction is more than $\alpha_{3}$, the upstream backwater level caused by streamline pier is the largest. As the square pier is becoming larger, the bicircular pier is gradually becoming the smallest Thus, three types of pier have different optimal ranges in the angle between the axis of the bridge pier and water flow direction. When the angle between the axis of the bridge pier and water flow direction is less than $\alpha_{2}$, the upstream backwater level caused by streamline pier is the smallest; when the angle between the axis of the bridge pier and water flow direction is more than $\alpha_{2}$, the upstream backwater level caused by bicircular pier is the smallest. 
EMME 2015

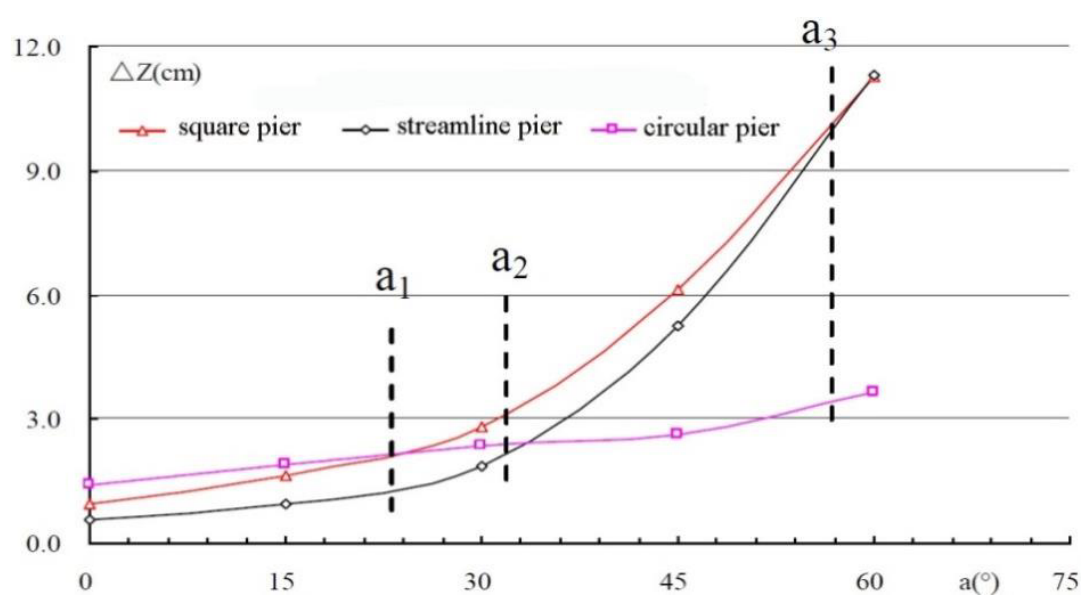

Figure 12. Relationship between the upstream backwater level and the pier type $(\mathrm{v}=1.5 \mathrm{~m} / \mathrm{s})$

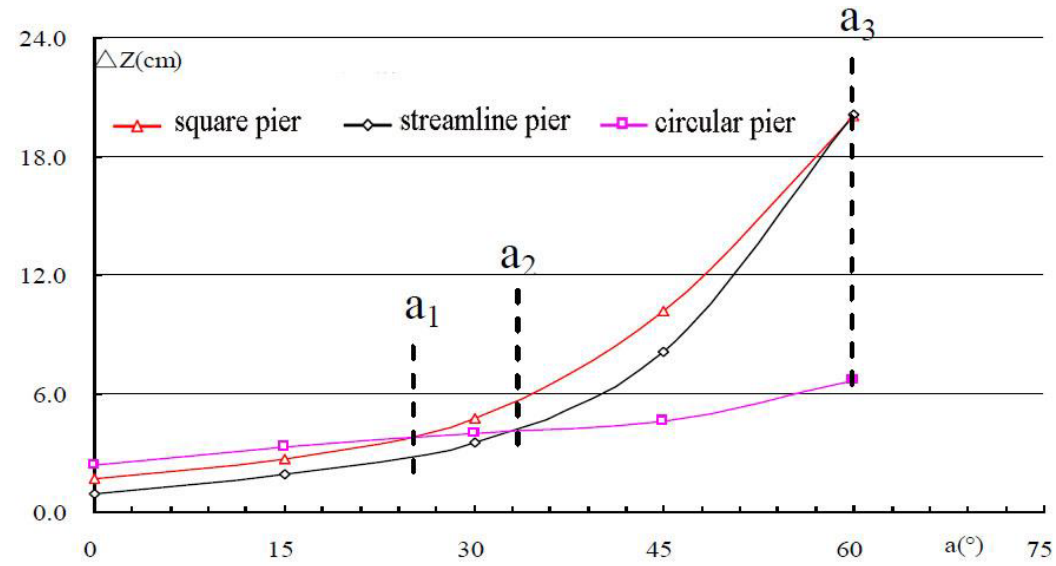

Figure 13. Relationship between the upstream backwater level and the pier type $(\mathrm{v}=2.0 \mathrm{~m} / \mathrm{s})$

Table 2. Test results of the relationship between the backwater level and the bridge pier type (Unit: $\mathrm{cm}$ )

\begin{tabular}{|l|l|l|l|l|l|l|}
\hline Pier type & Angle $\left(^{\circ}\right)$ & Water resistance ratio $(\%)$ & $0.5 \mathrm{~m} / \mathrm{s}$ & $1.0 \mathrm{~m} / \mathrm{s}$ & $1.5 \mathrm{~m} / \mathrm{s}$ & $2.0 \mathrm{~m} / \mathrm{s}$ \\
\hline \multirow{5}{*}{ Square pier } & 0 & 3.82 & - & 0.36 & 0.94 & 1.65 \\
\cline { 2 - 7 } & 15 & 6.80 & 0.24 & 0.70 & 1.65 & 2.64 \\
\cline { 2 - 7 } & 30 & 10.40 & 0.47 & 1.28 & 2.83 & 4.71 \\
\cline { 2 - 7 } & 45 & 15.48 & 0.81 & 2.68 & 6.12 & 9.13 \\
\cline { 2 - 7 } & 60 & 24.53 & 1.28 & 4.90 & 11.26 & 20.00 \\
\hline \multirow{5}{*}{ Streamline pier } & 0 & 5.45 & - & 0.24 & 0.59 & 0.94 \\
\cline { 2 - 7 } & 15 & 6.27 & 0.12 & 0.43 & 0.96 & 1.89 \\
\cline { 2 - 7 } & 30 & 9.18 & 0.24 & 0.94 & 1.89 & 3.54 \\
\cline { 2 - 7 } & 60 & 14.56 & 0.54 & 2.18 & 5.24 & 8.12 \\
\hline \multirow{5}{*}{ Bicircular pie } & 0 & 23.89 & 1.30 & 4.92 & 11.32 & 20.12 \\
\cline { 2 - 7 } & 15 & 5.00 & 0.12 & 0.71 & 1.41 & 2.36 \\
\cline { 2 - 7 } & 30 & 10.20 & 0.24 & 0.94 & 1.89 & 3.30 \\
\cline { 2 - 7 } & 45 & 11.60 & 0.36 & 1.18 & 2.36 & 4.00 \\
\cline { 2 - 7 } & 60 & 20.00 & 0.52 & 1.48 & 2.62 & 4.62 \\
\hline
\end{tabular}


MATEC Web of Conferences

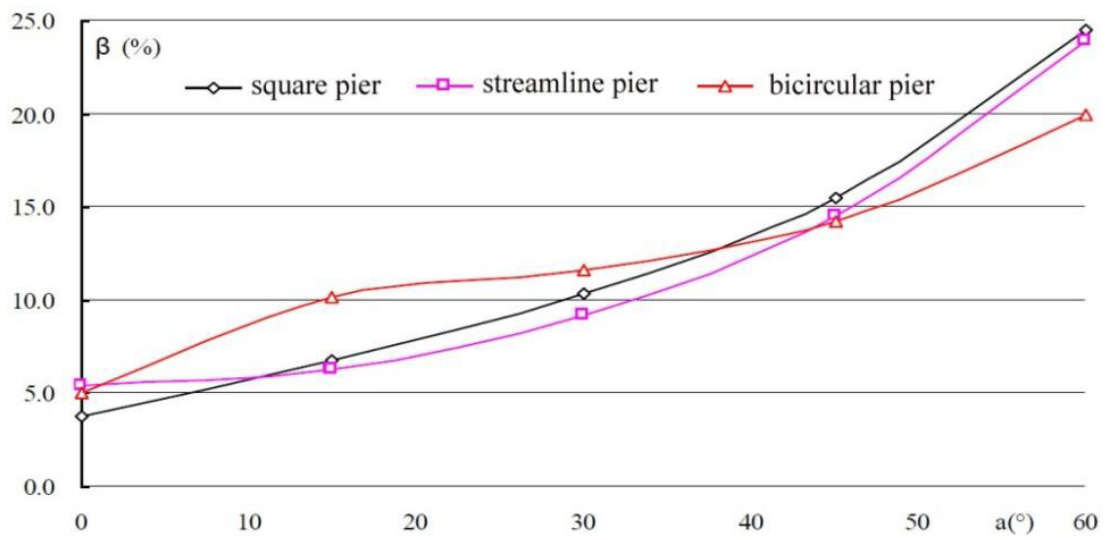

Figure 14. Relationship between the water resistance ratio and the water flow angle

According to different flow velocities, $\alpha_{1}, \alpha_{2}$ and $\alpha_{3}$ are slightly different. Table 3 has statistics. An average value of $\alpha_{1}$ is $23^{\circ}$, an average value of $\alpha_{2}$ is $36^{\circ}$, and an average value of $\alpha_{3}$ is $59^{\circ}$. Based on the above data and analysis, when the angle between the axis of the bridge pier and water flow direction is less than $36^{\circ}$, it should give priority to the streamline pier; when the angle between the axis of the bridge pier and the water flow direction is more than $36^{\circ}$, it should give priority to the bicircular pier.

Table 3. Statistics of strength angles of different bridge piers

\begin{tabular}{|l|l|l|l|l|l|}
\hline & $0.5 \mathrm{~m} / \mathrm{s}$ & $1.0 \mathrm{~m} / \mathrm{s}$ & $1.5 \mathrm{~m} / \mathrm{s}$ & $2.0 \mathrm{~m} / \mathrm{s}$ & $\begin{array}{l}\text { Average } \\
\text { value }\end{array}$ \\
\hline $\mathrm{a}_{1}$ & $15^{\circ}$ & $27^{\circ}$ & $24^{\circ}$ & $25^{\circ}$ & $23^{\circ}$ \\
\hline $\mathrm{a}_{2}$ & $44^{\circ}$ & $35^{\circ}$ & $33^{\circ}$ & $33^{\circ}$ & $36^{\circ}$ \\
\hline $\mathrm{a}_{3}$ & $59^{\circ}$ & $59^{\circ}$ & $59^{\circ}$ & $59^{\circ}$ & $59^{\circ}$ \\
\hline
\end{tabular}

The relationship between the water resistance ratio and the water flow angle is shown in Figure 14. For the bicircular pier, when the water flow angle is increased to a certain angle, the space between two front and back circular piers can pass through water. And the increase of water resistance ratio and backwater level is not obvious, so the bicircular pier should be adopted when the water flow angle is relatively large, which is consistent with the previous rules.

\section{CONCLUSION}

This paper carried out an experimental research on the physical model of wide water channel from the perspective of optimizing the bridge pier types and reducing backwater with the following main conclusions:

(1) When the frontier breadth of upstream face of the bridge pier is unchanged, there is an optimal profile curve of the bridge pier: the ratio between the convex breadth of the curve ( $b^{\prime}$ ) and the length of bridge pier (L) measures the degree of curvature of the curve, and the characteristic parameter in the profile curve of the bridge pier under the minimum backwater level $\left(b^{\prime} / L\right)$ is in the range of $0.071-0.083$. (2) Three kinds of commonly-used pier types - square pier, streamline pier and bicircular pier have different strength angles: If the angle between the axis of bridge pier and the water flow direction is less than $36^{\circ}$, it should give priority to the streamline pier; if the angel between the axis of bridge pier and the water flow direction is greater than $36^{\circ}$, then it should give priority to the bicircular pier.

The commonly-used method of reducing bridge backwater is to reduce water resistance ratio. That is, without increasing the breadth of the bridge pier, but with increasing the bridge span, it usually greatly increases the cost of the bridge construction. The research result shows the principle of selection of bridge piers under different water flow angles and parameters in the profile curve of the bridge pier under the minimum backwater level. Backwater can be reduced without a substantial increase of the engineering cost, which plays an important guiding role in the engineering construction of the bridge.

\section{REFERENCES}

[1] Hunt, J., Brunner, G.W \& Larock, B.E. 1999. Flow transitions in bridge backwater analysis. Journal of $\mathrm{Hy}$ draulic Engineering, 125 (9): 981-983.

[2] Seckin,G.,Yurtal,R. \& Haktanir,T. 1998. Contraction and expansion losses through bridge constrictions Journal of Hydraulic Engineering, 124 (5):546-549.

[3] Hao Lu. \& Dongguang Gao. 1991. Bridge hydraulics .Beijing: China Communications Press.

[4] United States Army Corps of Engineers. (Jiezhao Wang, Yuanxi Zhang, et al. Hydraulic design criteria. Beijing: Water Conservancy Press, 1982.

[5] Teaching and Research Section of Wuhan University of Hydraulic and Electrical Engineering, hydraulic calculation manual. Beijing: Water Conservancy Press, 1980. 
[6] The Third Railway Survey and Design Institute, hydrology of bridge crossing. Beijing: China Railway Publishing House, 1993.

[7] Zhongqing Jin.1989. The numerical solution of N-S equation and turbulence model. Hohai University Press.

[8] DHI Warer \& Environment. 2003. MIKE 11 Reference Manual: A Modelling System for Rivers and Channels. DHI Software.

[9] Kai Wang, Xudong Fu \& Guangxian Wang. 2006 Comparison of calculation methods of backwater at bridge piers. North-to-North Water Transfers and Water Science and Technology, 4 (6): 53-55.

[10]Beilei Qin. 2010. Analysis of calculation method of water resistance of the bridge. Guangdong Water Resources and Hydropower, (4): 1-11.

[11]Cuiling Sun, Xiaohui Xu, Di Wu, Xianfeng Wang \& Xuewen Liang. 2006. Analysis of mathematical model of water resistance of Foshan Bridge Group. Anhui Agricultural Sciences, 34 (1): 186-188.
[12] Linchun Xu, Dong Huang, Guodong Zheng. \& Bensheng Huang. 2008. Numerical simulation of the flood influence on Beijiang Baimiao Extra Large Bridge Engineering. Guangdong Water Resources and Hydropower, (1): 36-44.

[13]Fei Wu \& Meng Gan. 2009. Numerical simulation research of the influence on the river flow field by bigger angle between the axis of the pier group and the river flow direction. Journal of North China Institute of Water Resources and Hydropower, (2): 11-14.

[14]Qin Zhou, Chongqing Yin \& Zhan Zhang. 2011. Numerical simulation research of water resistance properties for the skew bridge pier group. Hydro-Science and Engineering, 30 (2): 29-31.

[15]Wei Ding, Hongwu Tang, Wenhong Dai \& Yang Xiao. 2011. Research of resistance influence factors of river bridges. Hydro-Science and Engineering, (4): 52-56. 